\title{
On Promoting the New Professional Farmers Cultivation by Local Agricultural Colleges and Universities
}

\author{
Liu Aichen \\ Jilin Agricultural University, Changchun, 130118, China. \\ 9558805@qq.com
}

Keywords: Localagricultural colleges, new professional farmers,cultivate .

\begin{abstract}
At present, the cultivation of professional farmers is urgent, and the local agricultural colleges consider the professional and technical personnel as the main responsibility; the local agricultural colleges must undertake the important task of cultivating, to improve the level of the development of agricultural economy in China. First, this paper introduces the local agricultural colleges in the new professional farmers cultivating the superiority, secondly it analyses the problems existing in the work in the new professional farmers cultivation, and in the final the paper puts forward the countermeasures to promote the new professional farmers cultivate, hoping to bring certain reference for related professionals.
\end{abstract}

\section{Introduction}

Our country is an agricultural country. The problem of agriculture, rural areas and farmers directly affects the stability of China's social and economic development, and in the midst of this, farmers is the core key to solve the problem of "agriculture, rural areas and farmers" in China, it is not only the direct beneficiaries of the new rural construction, but also the main force of the new rural construction. Therefore, both focus on the current, and considering the future, the construction of new socialist countryside, must be actively promoting the comprehensive qualities of farmers, cultivate them to become literate, understand technology, will operate a new type of farmers. Because of this, professional and technical personnel to develop agriculture as the main responsibility of the local agricultural colleges must give full play to its advantages in the field of talent, technology, etc, in cultivating new professional farmers play a more active role.

\section{The Advantages Of Local Agricultural Colleges In The New Professional Farmers Cultivating}

\subsection{Talent And Professional Advantages}

Relying on its own conditions for running a local agricultural college, the local agricultural college carries out adult education and vocational education for farmers, so as to effectively improve the comprehensive quality of the broad masses of farmers. Specifically, the agricultural colleges can take various measures to actively support "one town, one color", “ one village one product”, strengthening the farmers' planting and breeding technology. For example, local agricultural colleges can also rely on the local agricultural development the truth, extensive scientific technology services, through set up advisory station, training classes, remote services to help farmers solve the problems in the actual production and life, to better promote the development of local rural economy.

\subsection{The Advantage Of Scientific Research Innovation And Practical Technology Popularization}

Local agricultural colleges and universities on the scientific research level has the absolute leading position, because of this, the local colleges and universities should make full use of its advantages, to enhance investment in manpower and money, to speed up the research concerning the practical technology, so as to effectively solve the urgent needs of the farmers, better services for farmers. 


\section{Existing Problems in New Professional Farmers Cultivating by Local Agricultural Colleges}

For a long time, the local agricultural colleges in the process of cultivating new professional farmers are existing status and duties not clear phenomenon, quite a number of colleges and universities are not professional farmers, therefore, the current new professional farmers cultivating problems in the local agricultural colleges and universities mainly include the following:

\subsection{Cultivate the direction is not clear}

New professional farmers mainly divide into production-oriented professional farmers, serviceoriented professional farmers and operating several types such as professional farmers, but quite a number of professional in a current local agricultural college has focused on the research and development and production of crop variety, although the conform to the requirements of the production of professional farmers, but in a service-oriented professional farmers and business professional farmers cultivate two aspects are relatively lack, and cultivate the direction is not clear, has not yet been to carry out the necessary professional construction and supporting teachers, etc.

\subsection{The quality of cultivating object cannot be guaranteed}

In the current work to develop a new professional farmers cultivating, most of the cultivating object directly from the countryside, the comprehensive quality is relatively poor, many levels of education are in the middle school and the following, and age is relatively high, generally between 40 to 60 years old. In fact, the new professional farmers cultivate the best cultivation object is teenager groups, but most of the current local agricultural colleges and universities have opened a lot of technical agriculture disciplines, so in terms of admissions tend to be broad, and for the students' cultural quality request is not high also.

\subsection{The lack of teachers}

A new type of professional farmers cultivate local agricultural colleges in China work is still in its infancy, most of the agricultural colleges are not open for farmers to carry out professional training, and even some basic work, such as training materials preparation, practice base Settings and equipped with teachers are all very limited. Not only that, compared with other industries, the difficult degree of agriculture also relatively high, this also led to a lot of farmers engaged in cultivating talent loss, especially the talent of the "double division type", is a severe lack of more, to a large extent hindered the progress of new type of professional farmers cultivating work.

\subsection{Mismatch In More Graduates Professional}

In recent years, with the employment of university graduates in China gradually serious, a lot of local agricultural colleges under the heavy pressure of employment, the graduates were forced to quit during the period of school, my major to appear the phenomenon of a large number of professional mismatches. Especially in the current under the situation of farmers cultivating system has not yet been established, but there are a lot of agricultural college's graduates due to factors such as salary and prospects have turned from the beginning.

\section{Strategy Analysis of Promoting the New Professional Farmers Cultivating by Local Agricultural Colleges and Universities}

\subsection{Scientific And Reasonable Cultivating Plan}

New professional farmers cultivating goal is divided into three types: master certain productionoriented professional farmers of agricultural production technology, to master a certain service professional farmers, agricultural service skills and mastery of agricultural production technology, has the strong enterprising professional farmers of agricultural production and operation management experience. Because of this, local agricultural universities and colleges should be combined with cultivating goal, scientific and reasonable planning on breeding direction. For example, although the government administrative units to establish new professional farmers cultivating system, and is responsible for the guidance and management of professional farmers cultivating new work, but its itself is also a lack of experienced staff, as a result, the management of the local agricultural colleges and universities can combine government units and guide to courses in corresponding professional and content, targeted training professional talents. For example, in 
local agricultural colleges can also set up related scientific research team, encourage them to determine the market demand, combined with the relevant policies and regulations, set more scientific basis for future development direction and reference.

\subsection{The Cultivating Object of Different Level}

At present, the new work, in the cultivation of professional farmers not only advanced production technology, but also for the vast number of rural labor force to the popularization of advanced technology education. But it must be admitted that China's current new professional farmers cultivating object has the problem of quality is uneven, the serious influence the effect of breeding work. Because of this, to enhance the utilization efficiency of agricultural colleges cultivate resources, cultivating object must be detailed and scientific level classification, and cultivating objects of different levels. In particular, for some object in the cultivation of comprehensive quality is very poor, should continue by NongGuangJiao, radio and television university training institutions to foster or field guide; For some object in the cultivation of comprehensive quality in general, you can through the advisory station, training classes, such as remote service way to teach them the advanced professional knowledge; For some object in the cultivation of comprehensive quality is higher, can thoroughly taught to them, encouraging them to learn and master the operation and management of agriculture and agricultural industrialization development and so on many knowledge.

\subsection{Increase The Intensity Of A Complete Set Of Corresponding Teachers And Textbooks}

Local agricultural colleges in the aspect of teaching resources and teachers reserve has more obvious advantages, therefore, in view of the current teaching task in the new type of professional farmers cultivate, imperfect related work such as the status quo, local agricultural colleges and universities should be at the beginning of the cultivation work, part of agricultural teaching experience of teachers focus on training, and through the examination way up a batch of qualified teachers, for this part of the teachers from the treatment, the title preference, logistics and other aspects, thus the new professional farmers cultivate work to lay a solid foundation. At the same time, in the aspect of cultivating materials, local agricultural colleges should also be closely combined with market demand, on the basis of giving full play to the advantages of our professional, formulate reasonable teaching contents and teaching scheme as soon as possible, so as soon as possible to carry out the teaching work.

\subsection{Strengthen Graduates Employment Guidance}

At present, due to the imbalance of social and economic development in our country, graduate employment situation is grim, and the independent choosing ability are relatively weak and so on the many kinds of factors, a significant number of local agricultural colleges graduates in employment choice and their own professional work of mismatch. Although our country in recent years also encourage agricultural entrepreneurs have issued a series of preferential policies, but there is still more obvious phenomenon of brain drain. For this reason, local agricultural colleges must change the talent training mode, optimize professional structure, intensify their career planning education, effectively raise the quality of personnel training, and actively seek policy support of relevant government departments, devote herself to guide and encourage students to "three rural" work. For example, for independent back to the countryside for entrepreneurship students, after graduation can guide and help them to apply for relevant subsidies; For some relatively high comprehensive qualities of students, but also can guide or recommend them to work in the relevant cultivation of government departments.

\section{Conclusion}

To sum up, with the continuous development of China's socialist modernization construction, the new work must pay attention to in the cultivation of professional farmers, local agricultural colleges and universities as the training base of agricultural professional and technical personnel, must bear the burden of new professional farmers cultivating, as soon as they have culture, understand technology, will operate to be a new type of farmers, to better promote the development of China's socialist construction. 


\section{References}

[1]Xueping Huang,"Professional in higher vocational colleges cultivate new-type farmers thinking”, Journal of green science and technology,Dec.2014,pp.295-296.

[2]Yunfeng Cai and Zhili Yan,” Chinese and foreign new professional farmers cultivating pattern comparison study”,Journal of education research, Vol.1,2014,pp.154-157.

[3]Zhili Yan and Yunfeng Cai,”New professional farmers cultivate: historical evolution and innovation”,Journal of contemporary vocational education BBS, 2014,pp.59-64.

[4]Geyi Zhu,”New professional farmers training mode innovation and practice”, Journal of anhui agricultural science,Vol.32,2015,pp.357-359 + 372 .

[5]Rong Wang,’Professional farmers cultivating new farmers in the self education analysis”,Rural economy and technology, Vol.10,2016,pp.158-159.

[6]Zhao Heng. New professional farmers training experience of international comparison and reference [J]. Journal of continuing education study, 2016 preceding: 30-35. 